\title{
Childhood memories, family ties, sibling support and loneliness in ever-widowed older adults: Quantitative and qualitative results
}

\begin{abstract}
Family relationships play a major role in individuals' lives and can be a source of comfort, support, and protection during the entire life course. Particularly in the context of life events, such as widowhood, family relationships may be salient for (older) adults in coping with feelings of grief, loss and loneliness. Using Dutch survey data and 18 in-depth interviews from a subsample, this study examines the role of family relationships through the lifespan in reducing loneliness among ever-widowed older adults (i.e. persons who have at some time during their life experienced the death of a spouse). Particular attention was paid to childhood memories, family ties, and support from siblings. Quantitative analyses examined associations between loneliness and childhood experiences of relationships with parents, family ties, and sibling support.

Qualitative data elucidated how ever-widowed adults recall relations with parents and siblings and experience current family relations. Quantitative and qualitative data showed that emotional support from siblings reduced loneliness. Additionally, positive memories of childhood relationships and current family ties were negatively related to loneliness. In times of everincreasing longevity, work detailing how family relationships across the life course are supportive in alleviating loneliness is a key issue on the social research and policy agenda.
\end{abstract}

Keywords: Widowhood, Loneliness, Childhood Memories, Sibling Support, Family Ties Running Head: Widowhood, family relationships and loneliness

CITE AS:

Merz, E.-M., \& De Jong Gierveld, J. (2014). The role of childhood memories and sibling support in affecting loneliness in widow(er)s. Ageing \& Society.

DOI: $10.1017 / \mathrm{S} 0144686 \mathrm{X} 14001329$ 


\section{Introduction}

Family relationships play a major role in individuals' lives and can be a source of comfort, support and protection during the whole life course. Particularly in the context of life events, such as aging, health crises, or widowhood, family relationships may be particularly salient in helping (older) adults to cope with feelings of grief, loss, and loneliness. The family of origin is an important environment within which individuals form close and affective relationships that endure over the life course (Merz, Schuengel and Schulze 2007), including those with siblings and progeny. Relationship experiences with parents during childhood may be the seedbed for support exchanges between family members throughout life. Crosnoe and Elder (2004) for example examined adjustment and functioning in later life in association with childhood experiences (although in men only). Whether childhood experiences also play an adaptive role in reducing loneliness in ever-widowed older adults has yet to be examined.

Earlier work (Pai and Ha 2012; Utz et al. 2004) has shown that widowed adults often rely on their adult children for support in the period following widowhood. Relationships with and support from siblings may also be important: from a lifetime perspective, siblings have a central position in individuals' networks and are thought to again become important towards the end of the life course as long-lived relationships (White 2001).Siblings' common history of upbringing in the same parental home and a similar socialisation regarding norms and values leads to shared opinions that might be important especially in crisis situations and in times of need (De Jong Gierveld and Peeters 2003). Pinquart (2003) showed that divorced and widowed adults reported a higher quality of sibling relationships than adults in first marriage, and Cicirelli (1995) mentioned the relevance of siblings for emotional outcomes. Sibling support has been found to buffer against loneliness (De Jong Gierveld and Dykstra 2008), however very little work has examined the role of sibling support in later life and in association with negative life events such as widowhood. 
The current paper examines whether childhood experiences of parental relationships, current support from siblings, and the evaluation of family ties are associated with reduced loneliness in older ever-widowed men and women. We used survey data from the second wave of the Netherlands Kinship Panel Study (Dykstra et al. 2012), and an additional in-depth study of a subsample of 18 men and women who experienced widowhood to shed light on life course family ties and loneliness in widowed older adults.

\section{Family ties in childhood and adulthood}

Previous work has shown the general effect of positive relationships on various outcomes throughout life (Merz and Consedine 2009; Merz et al. 2007). Experiences, memories, and expectations about the availability and responsiveness of trusted figures during childhood are incorporated into a mental representation of the self, of others, and of relationships, which guides perceptions and behaviour in later relationships (Feeney 2008). Children who have developed good relationships and attachment security, based on experiences with parents, typically show positive views of the self and others and desire closeness within relationships across the life course (Kachadourian, Fincham and Davila 2004). They manage to maintain a balance between being autonomous and having satisfying relationships with others. Such children are expected to establish and maintain supportive relationships with family members during the adult life course until old age (Davila, Burge and Hammen 1997; Repetti, Taylor and Seeman 2002).

Early experiences characterised by stressful childhood environments and unavailability of trusted figures leads to the development of less positive representations of relationships in which either the self and/or relationship partners are negatively viewed. Persons who have developed such negative representations generally have pessimistic views regarding interactions with other people (Mikulincer, Shaver and Pereg 2003), associated with less social support exchange (Kobak and Sceery 1988). They have difficulties with intimacy accompanied by difficulties with balancing care giving and care seeking behaviour within significant relationships. Based on these 
considerations such adults are expected to have less satisfying and more distanced relationships with family members resulting in less support exchanges and higher loneliness during adulthood.

From a life course view, siblings occupy a unique position in individuals' networks. They are often the most long-lived relationships people have, starting with the shared parental home and similar socialisations. In early adulthood, sibling ties often become weaker and partners and own children become central in adult's networks. Later on, when confronted with death of or divorce from a partner, contact with siblings intensifies again (White 2001).

\section{Family support and wellbeing}

A large body of research has demonstrated a positive association between aspects of social support and wellbeing in later life (Reinhardt, Boerner and Horowitz 2006; Russell and Cutrona 1991; Seeman and 1996). Of particular relevance to the current work are data indicating that support stemming from within the family may be of particular importance to wellbeing in older adults (e.g., Attias-Donfut 2001; Grundy and Henretta 2006 for intergenerational support; Thomas 2010 for sibling support). Family support, however, is a complex construct (Uchino, Cacioppo and Kiecolt-Glaser 1996). Indeed, emotional and instrumental support may have differing associations with wellbeing (Zunzunegui, Béland and Otero 2001) and loneliness (Sánchez, De Jong Gierveld and Buz, 2014). Research by Voorpostel en Van der Lippe (2007), comparing support exchange between siblings (and friends), found that relationship quality between siblings was important in explaining the effective exchange of both practical and emotional support between siblings. Voorpostel, Van der Lippe and Flap (2012) have shown that those with supportive and less strained sibling relationships experienced fewer negative life events such as divorce or physical and psychological illnesses, suggesting a protecting role in exposure to negative life events. Siblings may function as important sources of support to their widowed brother or sister. How this relates to loneliness however is yet to be examined. Distinguishing between types of support, that is, emotional and practical support, may help to disentangle the complex associations between sibling support and loneliness. 
In general, family relationships have been identified as important resources for adults in maintaing or regaining health, life satisfaction, and wellbeing (e.g., Merz and Consedine 2009; Tesch-Römer, Motel-Klingebiel and Von Kondratowitz 2002). As suggested by Bengtson (2004), it is necessary to look beyond the nuclear family when examining the influential power of family ties. Therefore, not only the parental home but also adult family relationships, including the extended family network, may be important factors in predicting loneliness in widowed adults.

\section{Loneliness, widowhood and family network}

Perlman and Peplau (1981:31) defined loneliness as "the unpleasant experience that occurs when a person's network of social relations is deficient in some important way, either quantitatively or qualitatively". Central to this definition is that loneliness is a subjective and negative experience, and is the outcome of a cognitive evaluation of the match between the quantity and quality of existing relationships and relationship standards.

Living as a couple is the living arrangement that provides older men and women with the greatest possibilities for alleviating loneliness. The benefits individuals experience from romantic relationships are distinct from those of other social bonds: the romantic relationship has a unique position in the social networks of adults. Partner relationships are associated with various outcomes such as protection and care (Zeifman and Hazan 2008), wellbeing (Soons and Liefbroer 2008; Soons, Liefbroer and Kalmijn 2009), health (Musick and Bumpass 2012), and mortality (Drefahl 2012). Fulfilling and satisfying partnerships protect individuals from loneliness (De Jong Gierveld et al. 2009). Briefly, adults without a partner tend to be less insulated from loneliness (Dannenbeck 1995; Wenger et al. 1996). Several mechanisms can explain why the absence of a partner makes people more vulnerable to loneliness. First, a key structuring influence in the social network is missing: size and broader composition of the network are strongly linked to the presence of a partner (Musick and Bumpass 2012; Pinquart and Sörensen 2001). Persons living alone have smaller networks than those living with a partner. Second, when help is needed, persons living alone lack in-house support and, must seek assistance with others outside the 
household. Third, living alone is in many cases the result of the dissolution of a partner relationship. Those who remain alone after the death of a partner are specifically at risk of loneliness, and the effects on the intensity of loneliness are recognisable over a long period of time (Lopata 1996; Stevens 1995).

Involvement in relationships other than a romantic bond can also help to prevent or alleviate loneliness. Hagestad (1998) described the socially integrative role of the family, arguing that communication and historical conversations across generations help maintain continuity across life phases and strengthen a sense of belonging. The centrality of the parent-child bond in people's lives is undisputed (Rossi and Rossi 1990), particularly for those who live alone. Dykstra (1993) and Pinquart (2003) have shown, for example, that contact with children is more likely to reduce loneliness among formerly married than among married older adults. Siblings too are special in many ways (Bedford 1998; Cicirelli 1995; Connidis 1989); there is the common blood tie, the shared history of growing up together in the same parental home and having the same background. Many widows and widowers consequently rely on the long-standing network of siblings, an already-extant network (Scott et al .2007). The loss of a sibling has been found to contribute to loneliness among older persons (Gold 1987). Particularly at later ages, individuals tend to maintain emotionally close and rewarding contacts and increase interactions with siblings (Carstensen, Isaacowitz and Charles 1999). Taken together, the above mentioned evidence suggests that bonds formed in the parental home, as well as current ties from the close family network are key in predicting loneliness in widowed older adults.

\section{The current study and hypotheses}

Ample evidence has shown the general salient effect of positive and supportive family bonds. The current work intended to examine the role of lifetime family ties, i.e. childhood bonds, and sibling support for loneliness in ever-widowed older adults. In order to examine whether sibling support has additional predictive power in explaining loneliness, we simultaneously examine support from both siblings and children. 
We expected memories of positive relationships with fathers and mothers during childhood to be related to positive adult family ties (hypothesis H1). Stronger family ties in adulthood, that is, involvement in an extended family network in which family members are experienced as reliable and available, is then expected to reduce loneliness in older adults (hypothesis H2). Similarly, support from the sibling network characterised by affectiveness, mutual interest, and advice (i.e. emotional support) is hypothesised to predict reduced loneliness (hypothesis H3a).Conversely, practical support from siblings was hypothesised to have no relationship with loneliness because it may elicit unwanted feelings of dependency and might be characterised more by obligation than affective care (hypothesis $\mathrm{H} 3 \mathrm{~b}$ ).

To shed more light on the role of family relationships in loneliness in ever-widowed older adults and underlying processes, we combined quantitative and qualitative data from the NKPS. The use of multiple methods, for example a combination of qualitative and quantitative approaches, an approach which was first advocated for in the early 1970s (Denzin, 1970). Miles and Huberman (1984: 234) stated: "It is important having different kinds of measurement, which provide repeated verification of outcomes". The use of large-scale quantitative data and analyses provides knowledge about structures and processes that can be generalised to various populations. In addition, there is a growing recognition that qualitative studies may be critically important in bringing in-depth knowledge about the mechanisms behind these structures and processes (Manning and Smock 2005). For that reason we combined the quantitative analyses with qualitative in-depth data. By drawing on the quantitative data, we examined the association between loneliness and childhood experiences of parental relationships, family ties, support from siblings and adult children among ever-widowed women and men aged 50 and over. Using qualitative data from 18 semi-structured interviews, we further investigated how older adults recall their earlier relations with parents and siblings in the parental home and how they experience current relations with siblings and other family members.

\section{Method}


Participants and measures quantitative analyses

The data for the present work stem from the second wave of the Netherlands Kinship Panel Study (NKPS; Dykstra et al. 2012); a study intended to examine family and kinship relationships in the Netherlands. The NKPS is a representative panel survey among individuals aged 18 to 79 living in private households in the Netherlands. First wave data were collected among 8,161 main respondents during 2002-2004. Second wave data were collected in 2006/2007 with 6,026 of the former 8,161 NKPS main respondents being re-interviewed. The questionnaires in Wave 2 focused on the changes that had taken place in the lives of the respondents and their families since the first wave but also included new variables to shed more light on experiences within the parental home; these variables were central to the present study. All 218 older adults who met the study criteria, that is, those who experienced the death of a partner and were aged 50 or over, were selected for the quantitative analyses. Mean age was 70.52 years $(S D=7.29$, range 53-83) and 78 per cent were female. Of these respondents, 35 (16.1 per cent) were repartnered after the death of their former partner.

\section{$<$ Insert Table 1 about here>}

The scales measuring childhood experiences, support from adult children and siblings and current famly ties were designed for the NKPS by the scientific team. They all show high validity, good reliabilities and have been widely used in family research (Merz and Jak, 2013; Merz et al. 2008; Merz et al. 2009).

Childhood experiences. Two scales were used as indicators of intergenerational relationship quality during childhood: 'attachment to mother' and 'attachment to father'. The two scales each consisted of four indicators measuring closeness with, availability of the mother and or father and support and understanding within the relationship with mother and or father during childhood. An example for measuring availability in the relationship with mother is "I could always turn to my mother if I had problems". Items on both subscales were answered on a five point scale ranging from $1=$ strongly disagree to $5=$ strongly agree. An average score of the four 
single items was calculated. Higher values on the scales indicated stronger attachment to mother and father respectively. Cronbach's alpha was .94 for both scales.

Family ties. The quality of family ties and embedding in the family was measured on a scale including four indicators covering closeness, strength, information exchange, and cohesion within relationship with members from the extended family, including siblings, aunts, uncles, and cousins. Please note that no items about ties with individual members from the nuclear family were included in the present analysis. One example item is "The ties between members of my extended family are tightly knit". Respondents evaluated their family ties on a five point scale ranging from $1=$ strongly disagree to $5=$ strongly agree. Higher values on this scale represented stronger family ties. Cronbach's alpha for this scale was .85 .

Support from siblings and adult children. Emotional support was measured using two items referring to how much interest and advice (ranging between $1=$ not at all, $2=$ once or twice, and 3 = several times) siblings and or adult children provided to their widowed brother/sister or father/mother. Information on these aspects of support was available for a maximum of two siblings and two children. Cronbach's alpha for the emotional support variable, based on four items (i.e. interest and advice from two siblings/two children), was .72 for the siblings and .70for child support. Instrumental support consisted of two items measuring how much support with household chores and odd jobs (ranging between $1=$ not at all, $2=$ once or twice, and 3 = several times) siblings/adult children provided. Cronbach's alpha for the instrumental support variable, based on four items, was .64 for sibling and .66 for child support.

Loneliness. Loneliness was measured using the De Jong Gierveld 11 item loneliness scale (De Jong Gierveld and Kamphuis 1985), a widely used, psychometrically sound scale (Pinquart and Sörensen 2001; Van Tilburg and De Leeuw, 1991). The word loneliness is not used in any of the items in order to avoid triggering feelings of embarrassment and social stigma among lonely men and women. The scale consists of items covering the availability of enough people to talk to, sources of support, people to trust, people to feel close to, and friends to call on whenever needed. 
An example item is "There is always someone I can talk to about my day-to-day problems."Possible answers to the items were $0=n o, 1=$ more or less and $2=y e s$. Scale scores are based on dichotomous item scores; the answer 'more or less' always indicates loneliness. The scale score 0 refers to the absence of loneliness, the score 11 to ultimate loneliness (De Jong Gierveld and Van Tilburg 1999).Cronbach's alpha for this scale was .83.

Control variables. Previous research has shown that loneliness varies across demographic characteristics (Hawkley et al. 2008). Therefore, we included age (in years), gender, education (ranging from $1=$ incomplete elementary to $11=$ post graduate), number of siblings and number of children and a general measure of subjective health (ranging from $1=$ very poor to $5=$ excellent) as control variables in the quantitative analyses.

Quantitative analyses. Pearson correlations were used to calculate bivariate associations among the study variables. Multivariately, first a hierarchical regression was performed to determine the best linear combination of demographic and childhood attachment variables predicting the evaluation of current family ties. Second, demographic and childhood attachment variables, as well as the evaluation of current family ties and variables identifying current network characteristics (partner status, the number of children and siblings, and support received from children and siblings) were taken into account to predict loneliness.

\section{Participants and procedure qualitative analyses}

In order to elicit in-depth knowledge about the mechanisms behind the role of family relationships for loneliness in older adults, a total of 52 semi-structured interviews were conducted with NKPS respondents in the years 2008/9. Only respondents who at the end of the NKPS Wave 2 agreed to be re-interviewed were contacted. A professionally educated interviewer and the second author with extensive expertise in qualitative research conducted the interviewing. The subsample of 52 interviewees encompassed ever widowed and ever divorced adults. The criteria for inclusion in this specific study encompassed: NKPS respondent aged 50 or over(in Wave 2), ever-widowed, and having two or more children and two or more siblings. In total 18 
out of the 52 older adults in the subsample were eligible for this study. All interviews took place in respondents ${ }^{\prime}$ homes. Ten respondents were female and eight were male. The moment of widowhood dated back 4 to 36 years, with a mean of 19.7 years. In total 9 of the 18 respondents had started a new romantic partner relationship and shared living arrangements; the other nine were living alone.

Given the availability of basic information about the respondents, based on the quantitative data gathered in Waves 1 and 2 of the survey, the semi-structured interview-guide included only a specialised series of topics covering quality and support exchange within the relationships with children, siblings, and other family members. The focus was on positive, negative, and ambivalent aspects of the sibling relationships to investigate the mechanisms behind the comforting or discomforting function of sibling relationships (Bengtson 2004; Hogerbrugge and Komter 2012; Lowenstein 2007). The opening question was "How would you describe the relations with your family members, more specifically with your children, sisters and brothers?" Answers to these questions helped to elicit perceptions, experiences and evaluations of past and current relationships. Additional questions were formulated to clarify answers, in order to obtain a broad and detailed overview of the relationships between respondents and their siblings and children. The interview strategy also allowed flexibility to capture unexpected findings. Duration of the interviews varied between 60 and 90 minutes.

The information gathered was tape-recorded and consequently transcribed in order to prepare the data for entry into the qualitative data management system. The second author, who has extensive expertise in qualitative research, took the lead in analysing the data. Both authors have been intensively involved in exploring the coding categories and themes that emerged from the data. The analysis procedure started with open coding of the interview texts (LaRossa 2005). Next the coding categories were examined and compared for similarities and differences and brought together in several schemes of related categories. As expected, sibling bonds are not stable over time, but are formed and re-formed, improving and deteriorating, depending on 
important life events with which adults are confronted. Introducing additional elements of the life course offered the opportunity to reassemble meaningful pieces of information (Elder 1995). Coding schemes have been revised and expanded as our interpretations and explanations progressed. The analysis was completed by formulating theoretical propositions around the interactional processes elicited, while data saturation was discussed between researchers.

\section{Results}

\section{Descriptive quantitative results and correlations}

Table 1 and 2 display the descriptives of the main variables and their correlations. As can be seen from Table 2, loneliness was not correlated with our control variables, except for health. Neither age, gender, nor education was associated with loneliness, whereas poor health was related to increased loneliness. Attachment to father but not attachment to mother reduced loneliness. Regarding family support, emotional support received from children and siblings correlated with lower levels of loneliness in our widowed older respondents whereas practical support was not associated with loneliness. Stronger family ties also correlated with lower levels of loneliness.

\section{<Insert Table 2 about here>}

\section{Multivariate results}

Table 3 displays the results of the hierarchical regression analysis of current family ties on demographic control variables and childhood attachment. Of the control variables, only gender was significantly associated with family ties, in that women reported higher quality. Memories of relationships with parents during childhood, or attachment to mother and father, positively predicted the current evaluation of family ties. Entering these family history characteristics into the regression more than doubled the explained variance in current family ties (cf. Table 3).

<Insert Table 3 about here>

In a second regression (cf. Table 4), family history characteristics (i.e. childhood attachment) as well as current family network characteristics (i.e. partner status, number of 
children and siblings, adult child and sibling support) stepwise were used to predict loneliness in our ever-widowed older adults. Among the control variables gender and health related with loneliness, such that being male and poor health was associated with higher feelings of loneliness. Attachment to father and evaluation of family ties reduced loneliness (cf. Model 1). In the next steps, current network characteristics were entered. Having a new partner reduced loneliness. Model 3 investigated the role support from adult children may play in association with loneliness among older adults. Emotional support did reduce loneliness whereas number of children and practical support was not predictive. Model 4 took support from the sibling network into account. Both number of siblings and emotional support from siblings were negatively related with loneliness. In both models, the child and sibling support model increased the explained variance in loneliness from 18 to 20 per cent, indicating that support from siblings mattered in a similar way for positive outcome in older adults as adult child support. In our final model, all predictors were included simultaneously, explaining 25 per cent of the variance in loneliness. In this model, father attachment, partner status, and emotional support from children as well as number of siblings remained significant predictors of loneliness.

<Insert Table 4 about here>

\section{Outcomes qualitative analyses}

In order to better understand the possible mechanisms behind the associations among childhood relationships, current family bonds and sibling support, we examined how older everwidowed women and men described and evaluated the bonds with family and siblings in particular. Based on these descriptions several theoretical lines of thinking could be elicited. The most distinctive differentiation was between older adults who evaluate current sibling relationships as either positive or negative. Among both groups of respondents, those who evaluated their sibling bonds as positive or negative, the parental home was explicitly mentioned as one of the factors determining the quality of current relationships. Furthermore, many of the interviewees spontaneously mentioned the exchange of support, especially emotional support 
particularly in relation to widowhood, as one of the key characteristics of optimal sibling relationships in later life. Additionally, this study showed that for the nine respondents who mentioned having good relationships with brothers and sisters, this was associated with lower scores on the loneliness scale for almost all of them. These respondents underlined the blessings of warm relationships with brothers and sisters, being well aware of the vulnerability of these sibling bonds given the advanced age of the interviewed older adults. Non optimal sibling bonds proved to be associated with feelings of more intense loneliness. Those respondents mentioned the discomfort of weakened bonds with siblings.

In the next sections, we describe the comments of our respondents in detail. Firstly, we address the comments of those evaluating their sibling bonds as positive. Secondly, we address the comments of those who are dissatisfied and talking about weakened bonds with brothers and sisters.

\section{(I) The benefits of warm relationships with siblings}

Of the nine respondents who were positive about the quality of their sibling bonds, two referred spontaneously to the positive quality of the bonds in the parental home, and four of them spontaneously mentioned the high quality of current sibling support. Three out of these nine respondents discussed broadly the improvement in the quality of sibling relationships starting in later life, more specifically after the onset of widowhood; see also .

\section{$<$ Table 5 about here>}

Older adults who evaluated their sibling relationships as positive talked extensively about these bonds. Moreover, all but one of these adults had low scores on the loneliness scale as measured in Wave 2 of the NKPS. The beneficial facets of good sibling relationships were, for example, carefully described by a woman, widowed for 9 years, living as single mother with her children (\#6):

"My brother is very important to me, because we only have each other now. I mean (...) there are no other brothers and sisters alive anymore. Yes, if something happens, we can 
always count on each other, (...), yes, we share the problems, the joy, we share everything, really. If something happens, we are always there for each other, always. So, really very important for me, yes. My brother and I, we are ...er, our father was a problem drinker, you see, ... so we did not grow up in a balanced family.

Apparently, the bond with her brother was helpful in alleviating loneliness; although having to cope with the daily chores of running a household with dependent children, she did not feel lonely (score on the loneliness scale 0 ). The time perspective (including both childhood and ageing experiences) played an important role in her description of the warm sibling bond. Their problematic childhood experiences have welded the siblings together. This widow referred to the bond with her brother in the context of other brothers and sisters who had died already and are sorrowly missed.

Similarly, a widow, aged 73 years, living alone (\#19), describing her sibling relations positively, framed her answer explicitly in the perspective of ageing and the confrontation with the death of her partner and of siblings (who had migrated from the Netherlands to Canada): "A mid-week family reunion was organised last year, and all sisters and brothers (-in-law) they came over from Canada, especially for this. (...). It was a great success. (...) I organised everything. My brother died soon after the reunion and looking back I would say that made the reunion even more important. And then, especially when you find out that your brother falls ill and you call each other, (...) you keep in touch and my sister and I, we said, now it's just the two of us here and we have to be really nice to each other, that's what we said".

This widow also had a low score on the loneliness scale (score 1) and realised the importance of lasting sibling bonds in the light of ageing and death. As mentioned by both respondents, the death of brothers and sisters affected the bonds with siblings who were still alive. Older adults mentioned their honest wish to be in contact with surviving brothers and sisters, but sometimes 
valuable bonds are hardly replaceable, as aptly put forward by a widower of 77 years, widowed for 36 years, living alone (\#7):

“... and my youngest sister, she was really my closest confidant, and she died two years ago. And that (contact) always went by telephone, because she lived in America. But it is a lot cheaper nowadays to phone to America, so I would chat on the phone for at least an hour. But I was able to discuss things with her, look, (...) with my oldest sister, we are on good terms, but I can't have those conversations that I used to have with my youngest sister. And my oldest brother died too".

The vulnerability of valuable bonds was by most interviewees explicitly recognised and especially well understood by the oldest interviewees. Several touched upon the beneficial functions of good sibling bonds, especially if one of the siblings was very recently confronted with the death of a partner. The bereaved sibling was comforted, and more frequently than before the bereaved person was emotionally supported. Those 'in the same boat', that is those who experienced widowhood already in the past, were willing and prepared to comfort the newly bereaved. Their partly shared life course eased an optimal tuning of the interrelationship. The following quote shows how a long-term widow, aged 73 years (\#19) followed her heart in comforting her sister-inlaw:

\footnotetext{
"I kept in close contact with my sister-in-law, who was now also alone, because I understood how she felt..."
}

For this widow too, the positive bond with her sister-in-law was among the factors affecting her low intensity of loneliness (a score of 1 on the loneliness scale). More than one respondent consequently mentioned the recognition of how others felt in the particular situation of becoming a widower or widow as a valuable aspect of sibling bonds in later life:

"In situations when it was needed, yes, then we were really there for each other, yes. But that was also because he lost his wife three years ago due to cancer and eh, then people often really change. From, eh, being an optimistic and easy going person and now, having 
to face it yourself then all over sudden it was different. And then, you understand a lot more of what others have to face" (widow for 32 years, 62 years of age; \#41).

This widow scored much higher on the loneliness scale (score 7). This score probably indicated that sibling contacts are important elements of the total social network, but the shortage of other supporting relationships in her network might have had a more decisive effect on the experienced intensity of loneliness.

In the citations shown until now, the most precious sibling bonds were characterised by emotional support, formulated as: 'understanding', 'being one's best confidante', and 'we are there, if something happens'. Interviewees accentuated that this emotional support became more and more important while ageing. In contrast, instrumental support between siblings tended to fade away. Several interviewees were filled with regret or nostalgia for times gone by. One of them, a widower for 32 years, now 81 years of age (\#78) formulated these feelings as follows:

"It's like this, if something needed to be moved, then we [as siblings] always helped out, that goes without saying. Then everyone helped. But it has become less and less. (...)But, we have children and grandchildren now, who can also do the job. The job has been taken over".

In conclusion, exchange of emotional support, being one's best confidante, were central categories of quotations of older adults involved in warm and positively evaluated sibling bonds. Moreover, most of the widows and widowers cited in this context were characterised by low levels of loneliness. Apparently, they had a social network distinguished - among others - by good sibling contacts that contributed to the experience of low levels of loneliness. One of the respondents, however, scored high on the loneliness scale. Hence, there was no exclusive relationship between one aspect of the social network - in this case the sibling bonds - and the overall evaluation of one's social environment as lonely. (II)The enduring discomfort of weakened sibling relationships and the wish for restoration 
Nine of the respondents were involved in sibling relationships characterised as ambiguous or even full of conflicts. Such non-optimal sibling bonds proved to be associated with feelings of discomfort. Sometimes the less optimal bonds with siblings dated back to the period in the parental home, as was explicitly and spontaneously mentioned by two of our respondents. For two of the respondents other events later in life were held responsible for the weakening of sibling ties. The lack of support from siblings was mentioned as an important facet of current life; see also Table 5. Most of the interviewees continued too long to discuss restoration of the bonds or reconciliation.

The comments of older adults who evaluated their current sibling bonds as 'reasonable', 'not good' or 'not good at all' were characterised by sorrowful descriptions of bonds with brothers and sisters. Interviewees explicitly referred to relational conflicts or even broken off sibling relationships during interviews. Several examples illustrate the sadness of those involved; one such example is the story of a widow for 10 years, 55 years of age (\#94; loneliness score 2):

"The sibling relationships have been difficult for quite a while. Totally driven apart, actually. Especially with my sister. We, my sister and I were very close sisters. (...) And then, she had marriage problems and during that time, I had just met Huub [an intimate friend of hers, JG], and Huub said something about her husband (...), and that's why everything went wrong. My sister blamed Huub for this and indirectly me too. (...) And then we did not see one another for a long period of time (...). In the past we, as brothers and sisters, always supported each other. That was necessary. Yes, we supported each other through thick and thin (...). (her eyes fill with tears)"'.

There were older adults who were more than incidentally involved in sibling conflicts. This is the story of a widow, now aged 75 years, who cared for her first husband until he died after a long period of illness and hospitalisation. She became a widow at age 57. A selection of events out of her life story, which illustrate multiple frictions with siblings: 
"The sibling relationships are poor. For a long time there was disagreement between my youngest sister and my oldest sister and I was the one in the middle. (...) Now, my youngest sister also had an argument with my brother (...) My sister has broken with the whole family, and now also with me. This has given me a lot of grief (...). No, there is no support giving or receiving in this family, never listening to one another”. (75 years, \#52). This widow scored very high (9) on the loneliness scale. Multiple conflicts can in the end lead to the loss of hope for restoration of the bonds and to intense loneliness. Faced with this situation, older adults were more or less forced to accept the emptiness of missing relationships, feeling rejected and losing their trust and confidence in close relationships. The negatively experienced sibling relationships and the related intense loneliness could become so overwhelming that older adults did not see any light at the end of the tunnel. This reality of a widow aged 80 years (\#44) was expressed as follows:

"I have nobody"

and she scored 11, the highest score on the loneliness scale. She was confronted with the death of her first and recently with the death of her second husband. In answering the question: 'Has someone supported you and your husband during the period of his terminal illness'? she said: "No, no, because I have nobody. I have really no person..."

The moderate feelings of loneliness of a long-term widow, now 51 years of age (\#35; score of 4on the loneliness scale) proved to be related to the breaking up of a group of four sisters. Three out of the four were still in close contact. Our interviewee apparently envied the bonds between the three sisters and was deeply unhappy with her 'staying aside'. She formulated the situation as follows:

“Er (...), reasonable. Well, how shall I say it. (...) We did not quarrel or anything, we could always rely on each other if needed. But we were not very close. I believe that those three together, they have more contact with each other. 
In conclusion, our data showed the effects of missing the exchange of emotional support with brothers and sisters. Several of the interviewees were stricken by grief, as became clear from the comments elicited, but also from their behaviour: some of the respondents started crying while describing their broken off relationships with siblings. In addition, our data illustrated the relationship between the evaluation of bonds with social network members as deficient, and the intensity of loneliness.

\section{Discussion}

Our results provide a thorough approach to shedding light on the role of siblings in older adults' social networks - both in terms of size and composition and in terms of the evaluative and supportive aspects of these networks - by combining qualitative and quantitative data. Below, we discuss these results more fully, considering the unique role of childhood memories and current family relations for loneliness after widowhood.

\section{Family Ties- the Role of Attachment to Mother and Father}

Experiences and memories of parents as a reliable resource in problem solving, as supportive, as (a) close figure(s), and as understanding, have been found to positively predict current evaluation of the family network (H1 confirmed) which in turn associated with loneliness such that positive family ties were related to reduced loneliness (H2 confirmed). Although previous research has always acknowledged the central role of primary caregivers, usually the mother, for the development of children, only few studies have extended this work to covering the whole life course well into old age (Van IJzendoorn and Bakermans-Kranenburg 2010).As shown by Grossmann, Grossmann and Kindler (2005), childhood experiences with primary caregivers influenced young adults' thoughts and feelings about close relationships. Generally, the current work, based on a combination of quantitative and qualitative data, gives some insight into the even farther-reaching influences that positive relationships in childhood can have on adult relations and the evaluation of family ties in older age. In addition, experiences and memories of the father as a reliable resource in problem solving, as supportive, a close figure, and as 
understanding, have been found to reduce loneliness in our widowed respondents. Why attachment to mothers did not associate with loneliness in our analyses while attachment to father did is not easy to explain. Recent work, however, has shown that fathers play a special and sometimes unique role in the upbringing of children and contribute specific features to their social and emotional development (Mallers et al. 2010) well into adulthood (Gilligan et al. 2013). Particularly in stimulating exploration fathers have been shown to be important figures in children's development (Grossmann, Grossmann, Kindler and Zimmermann 2008). It may well be that fathers are important in stimulating contact beyond the parental home whereas mothers have been shown to play important roles in comforting and soothing (Baumrind 1980; Grossmann et al. 2008) and in shaping emotional experiences (Mallers et al. 2010). The current association between positive memories of childhood relations with a father may have provided our respondents with social skills and capacities leading to more supportive networks in adulthood upon which they can rely after widowhood. Our qualitative results also referred to the importance of the family of origin for adult functioning and the maintenance and quality of siblings bonds in particular. Interestingly, a problematic family home may have led to better sibling bonds as protection. Although not explicitly asked, several of our qualitative respondents mentioned their parental home and childhood situation when describing the current bonds with family, again confirming the importance of childhood experiences for adult outcome.

\section{Sibling Support and Loneliness in Older Adults}

Due to ageing and life events such as widowhood, older adults have to rely on other close and emotionally rewarding figures (Carstensen et al. 1999; Doherty and Feeney 2004). Our quantitative results indicated that relationships with brothers and sisters can play a role in reducing loneliness in older ever-widowed adults. Siblings can contribute to the wellbeing of their brothers and sisters. Both sibling structure and relationship quality have been shown to associate with wellbeing in adolescents (Vogt Yuan 2009). Similarly, number of siblings, and especially the emotional support received from siblings proved to be associated with lower levels of loneliness 
in older adults (confirming H3a). These quantitative results were paralleled by information from the in-depthinterviews. Those who described their relationships with siblings as characterised by emotional support tended to reported low levels of loneliness. They used warm and sympathetic words to refer to the meaning of close sibling relationships. Bonds with siblings were based on regular visits to one another, but also on phoning each other. Life course events and related moves to other places require maintaining bonds over long distances. This is especially true for siblings confronted with the out-migration of brothers and sisters. Several of the interviewees mentioned that brothers or sisters had migrated from the Netherlands to Canada or the United States. In these cases, emotionally supporting the widowed sibling is realised via long distance calls, and occasionally via visits and family reunions.

Our interviewees explicitly mentioned that they were well aware of the ageing process and the risks of losing their loved ones, now that they as brothers and sisters were aging. Several of them described in detail the bonds with a sister or brother who passed away, and how intensely this person is missed. The need to be in close contact with brothers and sisters, who still are among them, was expressed. Additionally, those siblings who were in the same boat after the death of their partners stated explicitly that they tried to comfort one another, because they could empathize and shared the feeling of their loss. In the interviews, respondents also referred to practical help exchange, which was formerly a sibling task but was taken over by the younger generation. As expected (H3b) our quantitative results showed that indeed practical sibling support did not predict loneliness.

In research until now, frequently ignored is the situation of adults who, confronted with negative life events such as widowhood, evaluated their contacts with siblings as not good. Our study showed the overall sad and miserable situations of older widows and widowers when sibling relationships did not meet expected quality. The comments of older adults who evaluated their current sibling bonds as 'not good' or 'not good at all' were characterised by sometimes heartbreaking descriptions of ties that were deteriorated or even broken down. Many of them 
envied those siblings that were still in contact; others yearned for restoration of the bonds. Our data showed an association between sibling relationships evaluated as warm or emotionally supportive and lower levels of loneliness. On the other hand, those interviewees who identified sibling relationships as not good at all were more frequently characterised by moderate or strong feelings of loneliness. Many recently widowed older adults received increased social support from the family network that protected against loneliness to a certain extent. Later on however, such contact and support started to decrease (Guiaux, Van Tilburg and Broese van Groenou 2007), leading to higher risks of loneliness. For that reason, it may be important to know more about the functioning of the sibling part of the social network. Siblings, as part of the social relationships 'given by birth', are supposed to be less prone to network instability and to continue to function as a safety network in fighting the onset and continuation of loneliness.

\section{Limitations}

Although it contributes to our understanding of the role of family relationships on loneliness after widowhood by paying particular attention to sibling support based on both quantitative and qualitative data, the current study is not without limitations. First, we had to rely on retrospective measuring of childhood experiences. Adult respondents were asked to recall their experiences with parents before age 15. Evidence in childhood abuse and neglect studies (cf. Hardt and Rutter 2004 for an overview) showed that adverse life events in childhood tend to be correctly recalled or underestimated when retrospectively recalled in adulthood. Less is known, however, about the correct recalling of positive relationship aspects in their childhood experiences by adults. McCormick and Kennedy (1994) did find continuity between retrospective childhood attachment and current adolescent attachment measures. However, whether this continuity holds until late adulthood remains uncertain.

Second, no valid quantitative measures of sibling conflict were available from the survey. Although respondents were asked about negativity and conflict in their relationships with family members, the items referring to sibling relationships were very skewed and showed no to little 
variance. Therefore, they could not be used in the quantitative analyses. In addition, the interview data were collected after the survey data. For better compatibility between the quantitative and qualitative reports, it would have been valuable to use more parallel measures and timing.

In analysing the qualitative data, it was shown that experiencing warm sibling bonds was associated with lower loneliness, and deteriorated or broken sibling relationships were associated with higher levels of loneliness. The latter group used a varied set of words to indicate feelings of sadness and grief. However, none of them explicitly used the word loneliness to describe their feelings. We interpret this to be associated with the social stigma and taboo surrounding the phenomenon of loneliness. It was only by using their scores on the quantitative loneliness scale that we were able to connect the evaluation of relationship quality with siblings and loneliness. On the other hand, this procedure illustrates the rich potential of a research design that encompasses both quantitative and qualitative data.

\section{Concluding remarks and implications for policy making}

In sum, the current study was a first step in elucidating some of the complex associations family relations might have with loneliness in widowed older adults. Both the quantitative and qualitative results showed that family bonds, in particular sibling relationships and emotional support may be major resources in reducing loneliness. In addition, childhood memories of relationships with a father have been found to predict loneliness. Attachment concepts may help link personal childhood experiences to social circumstances (Merz et al. 2008) as attachment ties can be considered the first social ties through which children develop and experience future relationships. This process may be key to elucidating the complex interplay among family relations throughout the whole life course, from childhood well into old age.

Family relationships often stir strong emotions, positive and negative, and play an important role in social health, especially during negative life events. It should be taken into account that meaningful and long lasting relations between family members in all phases of the lifespan cannot be taken for granted (Kaufmann, Kuijsten, Schulze and Strohmeier 2002) 
although they are crucial for our wellbeing and the very meaning of life. Based on findings such as these, awareness may be raised that maintaining high quality relationships with one's siblings, children or parents requires active commitment. Letting relationships deteriorate might, in the long run, lead to less wellbeing. Although there is a well-developed practice for supporting parent-child relationships when children are young, the current findings suggest that such practice, for example family counseling, may become relevant again as individuals are ageing and experience the death of a spouse. 


\section{References}

Attias-Donfut, C. 2001. The dynamics of elderly support: the transmission of solidarity patterns between generations. Zeitschrift für Gerontologie und Geriatrie, 34, 1, 9-15.

Baumrind, D. 1980. New directions in socialization research. American Psychologist, 35, 7, 63952.

Bedford, V.H. 1998. Sibling relationships troubles and well-being in middle and old age. Family Relations, 47, 4, 369-76.

Bengtson, V.L. 2004. Beyond the nuclear family. The increasing importance of multigenerational bonds. Journal of Marriage and Family, 63, 1, 1-16.

Carstensen, L.L., Isaacowitz, D.M. and Charles, S.T. 1999. Taking time seriously. A theory of socioemotional selectivity. American Psychologist, 54, 3, 165-81.

Cicirelli, V.G. 1995. Sibling Relationships Across the Life Span. Plenum Press, New York. Connidis, I.A. 1989. Siblings as friends in later life. American Behavioral Scientist, 33, 1, 81-93. Crosnoe, R. and Elder, G.H. Jr. 2004. From childhood to the later years: Pathways of human development. Research on Aging, 26, 6, 623-54.

Dannenbeck, C. 1995. Im Alter einsam? Zur Strukturveränderung sozialer Beziehungen im Alter [On the structural change of social relationships at older age]. In H. Bertram (ed.), Das Individuum und seine Familie [The Individual and his/her Family]. Leske + Budrich, Opladen, 125-56.

Davila, J., Burge, D. and Hammen, C. 1997. Why does attachment style change? Journal of Personality and Social Psychology, 73, 4, 826-38.

De Jong Gierveld, J., Broese van Groenou, M., Hoogendoorn, A.W. and Smit, J.H. 2009. Quality of marriages in later life and emotional and social loneliness. Journal of Gerontology: Social Sciences, 64B, 4, 497-506.

De Jong Gierveld, J. and Dykstra, P.A. 2008. Virtue is its own reward? Support-giving in the family and loneliness in middle and old age. Ageing \& Society, 28, 2, 271-87. 
De Jong Gierveld, J. and Kamphuis, F. 1985. The development of a Rasch-type loneliness scale. Applied Psychological Measurement, 9, 3, 289-99.

De Jong Gierveld, J. and Peeters, A. 2003. The interweaving of repartnered older adults' lives with their children and siblings. Ageing \& Society, 23, 2, 187-205.

De Jong Gierveld, J. and Van Tilburg, T.G. 1999. Manual of the Loneliness Scale. Amsterdam: VU University.

Denzin, N.K. 1970. The Research Act: A Theoretical Introduction to Sociological Methods. Aldine de Gruyter, Chicago.

Doherty, N.A. and Feeney, J.A. 2004. The composition of attachment networks throughout the adult years. Personal Relationships, 11, 4, 469-88.

Drefahl, S. 2012. Do the married really live longer? The role of cohabitation and socioeconomic status. Journal of Marriage and Family, 74, 3, 462-75.

Dykstra, P.A. 1993. The differential availability of relationships and the provision and effectiveness of support to older adults. Journal of Social and Personal Relationships, 10, $3,355-70$.

Dykstra, P.A., Kalmijn, M., Knijn, T.C.M., Komter, A.E., Liefbroer, A.C. and Mulder, C.H. 2012. Codebook of the Netherlands Kinship Panel Study, a Multi-Actor, Multi-Method Panel Study on Solidarity in Family Relationships, Wave 2. NKPS Working Paper, No. 8. The Hague, Netherlands: Netherlands Interdisciplinary Demographic Institute.

Elder, G.H. Jr. 1995. Life trajectories in changing societies. In Bandura, A. (ed.), Self-Efficacy in Changing Societies. Cambridge University Press, New York, 46-68.

Feeney, J.A. 2008. Adult romantic attachment. Developments in the study of couple relationships. In Cassidy, J. and Shaver, P.R. (eds.), Handbook of Attachment. Theory, Research, and Clinical applications. Guilford, New York/London, 456-81. 
Gilligan, M., Suitor, J., Kim, S. and Pillemer, K. 2013. Differential effects of perceptions of mothers' and fathers' favoritism on sibling tension in adulthood. Journal of Gerontology, Series B: Psychological Sciences and Social Sciences, 68, 4, 593-98.

Gold, D.T. 1987. Siblings in old age: Something Special. Canadian Journal on Aging/La Revue canadienne du vieillissement, 6, 3, 199-216.

Grossmann, K., Grossmann, K.E. and Kindler, H. 2005. Early care and the roots of attachment and partnership representations. In Grossmann, K.E., Grossmann, K. and Waters, E. (eds.), Attachment From Infancy to Adulthood. The Major Longitudinal Studies. Guilford, New York/London, 98-136.

Grossmann, K., Grossmann, K.E., Kindler, H. and Zimmermann, P. 2008. A wider view of attachment and exploration. The influence of mothers and fathers on the development of psychological security from infancy to young adulthood. In Cassidy, J. and Shaver, P.R. (eds.), Handbook of Attachment. Theory, Research, and Clinical Applications. Guilford, New York/London, 857-79.

Grundy, E. and Henretta, J.C. 2006. Between elderly parents and adult children: a new look at the intergenerational care provided by the 'sandwich generation'. Ageing \& Society, 26, 5, 70722.

Guiaux, M., Van Tilburg, T. and Broese van Groenou, M.I. 2007. Changes in contact and social support exchange in personal networks after widowhood. Personal Relationships, 14, 3, 457-73.

Hagestad, G. 1998. Towards a society for all ages: new thinking, new language, new conversations. Unpublished manuscript, New York.

Hardt, J. and Rutter, M. 2004. Validity of adult retrospective reports of adverse childhood experiences: review of the evidence. Journal of Child Psychology and Psychiatry, 45, 2, 260-73. 
Hawkley, L.C., Hughes, M.E., Waite, L.J., Masi, C.M., Thisted, R.A. and Cacioppo, J.T. 2008. From social structural factors to perceptions of relationship quality and loneliness: the Chicago health, aging, and social relations study. The Journals of Gerontology: Social Sciences, 63B, 6, S375-84.

Hogerbrugge, M.J.A. and Komter, A.E. 2012. Solidarity and ambivalence: Comparing two perspectives on intergenerational relations using longitudinal panel data. The Journals of Gerontology: Social Sciences 67B, 3, 372-83.

Kachadourian, L.K., Fincham, F. and Davila, J. 2004. The tendency to forgive in dating and married couples: The role of attachment and relationship satisfaction. Personal Relationships, 11, 3, 373-93.

Kaufmann, F.-X., Kuijsten, A., Schulze, H.-J. and Strohmeier, K.P. (Eds.) 2002. Family Life and Family Policies in Europe. Volume 2. Problems and Issues in Comparative Perspective. Oxford University Press, Oxford, United Kingdom.

Kobak, R.R. and Sceery, A. 1988. Attachment in late adolescence: Working models, affect regulation, and representations of self and others. Child Development, 59, 1, 135-46.

LaRossa, R. 2005. Grounded theory methods and qualitative family research. Journal of Marriage and Family, 67, 4, 837-57.

Lopata, H.Z. 1996. Current Widowhood; Myths and Realities. Sage, London.

Lowenstein, A. 2007. Solidarity-Conflict and ambivalence: Testing two conceptual frameworks and their impact on quality of life for older family members. Journal of Gerontology: Social Sciences, 62B, 2, S100-07.

Mallers, M.H., Charles, S.T., Neupert, S.D. and Almeida, D.M. 2010. Perceptions of childhood relationships with mother and father: daily emotional stressor experiences in adulthood. Developmental Psychology, 46, 6, 1651-61.

Manning, W.D. and Smock, P.J. 2005. Measuring and modeling cohabitation: New perspectives from qualitative data. Journal of Marriage and Family, 67, 4, 989-1002. 
McCormick, C.B. and Kennedy, J.H. 1994. Parent-child attachment working models and selfesteem in adolescence. Journal of Youth and Adolescence, 23, 1, 1-18.

Merz, E.-M. and Consedine, N.S. 2009. The association of family support and wellbeing in later life depends on attachment style. Attachment \& Human Development, 11, 2, 203-21.

Merz, E.-M. and Consedine, N.S. 2012. Ethnic group moderates the association between attachment and wellbeing in later life. Cultural Diversity and Ethnic Minority Psychology, 18, 4, 404-15.

Merz, E.-M., Consedine, N.S., Schulze, H.-J. and Schuengel, C. 2009. Wellbeing of adult children and ageingparents:associationswithintergenerationalsupportandrelationshipquality. Ageing \& Society, 29, 5, 783-802.

Merz, E.-M. and Jak, S. 2013. The long reach of childhood. Childhood experiences influence close relationships and loneliness across life. Advances in Life Course Research, 18, 3, 212222.

Merz, E.-M., Schuengel, C. and Schulze, H.-J. 2007. Intergenerational solidarity: An attachment perspective. Journal of Aging Studies, 21, 2, 175-86.

Merz, E.-M., Schuengel, C. and Schulze, H.-J. 2008. Inter-generational relationships at different ages: an attachment perspective. Ageing \& Society, 28, 5, 717-36.

Mikulincer, M., Shaver, P.R. and Pereg, D. 2003. Attachment theory and affect regulation: The dynamics, development, and cognitive consequences of attachment-related strategies. Motivation and Emotion, 27, 2, 77-102.

Miles, M.B. and Huberman, A.M. 1984. Qualitative Data Analysis: A Sourcebook of New Methods. Sage, Beverly Hills.

Musick, K. and Bumpass, L. 2012. Reexamining the case of marriage: Union formation and changes in well-being. Journal of Marriage and Family, 74, 1, 1-18.

Pai, M. and Ha, J.-H. 2012. Impact of widowhood on parent-child relations: Does parents' personality matter? Journal of Marriage and Family, 74, 3, 494-509. 
Perlman, D. and Peplau, L.A. 1981. Toward a social psychology of loneliness. In Gilmour, R. and Duck, S. (eds.), Personal Relationships 3: Personal Relationships in Disorder. Academic Press, London, 31-43.

Pinquart, M. 2003. Loneliness in married, widowed, divorced, and never-married older adults. Journal of Social and Personal Relationships, 20, 1, 31-53.

Pinquart, M. and Sörensen, S. 2001. Influences on loneliness in older adults: A meta-analysis. Basic and Applied Social Psychology, 23, 4, 245-66.

Reinhardt, J.P., Boerner, K. and Horowitz, A. 2006. Good to have but not to use: Differential impact of perceived and received support on well-being. Journal of Social and Personal Relationships, 23, 1, 117-29.

Repetti, R.L., Taylor, S.E. and Seeman, T.E. 2002. Risky families: Family social environments and the mental and physical health of offspring. Psychological Bulletin, 128, 2, 330-66.

Rossi, A.S. and Rossi, P.H. 1990. Of human bonding, parent-child relations across the life course. Aldine de Gruyter, New York.

Russell, D.W. and Cutrona, C.E. 1991. Social support, stress, and depressive symptoms among the elderly: Test of a process model. Psychology and Aging, 6, 2, 190-201.

Sánchez, M. M., De Jong Gierveld, J. and Buz, J. (2014). Loneliness and the exchange of social support among older adults in Spain and the Netherlands. Ageing \& Society, 34, 2, 330-54.

Scott, S.B., Bergeman, C.S., Verney, A., Longenbaker, S., Markey, M.A. and Bisconti, T.L. 2007. Social support in widowhood: A mixed methods study. Journal of Mixed Methods Research, 1, 3, 242-66.

Seeman, T.E. 1996. Social ties and health: The benefits of social integration. Annals of Epidemiology, 6, 5, 442-51.

Soons, J.P.M. and Liefbroer, A.C. 2008. Together is better? Effects of relationship status and resources on Young adults' well-being. Journal of Social and Personal Relationships, 25, $603-24$. 
Soons, J.P.M., Liefbroer, A.C. and Kalmijn, M. 2009. The long-term consequences of relationship formation for subjective well-being. Journal of Marriage and Family, 71, 5, 1254-70.

Stevens, N. 1995. Gender and adaptation to widowhood in later life. Ageing \& Society, 15, 1, 3758.

Tesch-Römer, C., Motel-Klingebiel, A. and Von Kondratowitz, H.-J. 2002. The relevance of the family network for the quality of life of elderly people: comparing societies and cultures. Zeitschrift für Gerontologie und Geriatrie, 35, 4, 335-42.

Thomas, P.A. 2010. Is it better to give or to receive? Social support and the well-being of older adults. Journal of Gerontology: Social Sciences, 65B, 3, 351-57.

Uchino, B.N., Cacioppo, J.T. and Kiecolt-Glaser, J.K. 1996. The relationship between social support and physiological processes: A review with emphasis on underlying mechanisms and implications for health. Psychological Bulletin, 119, 3, 488-531.

Utz, R.L., Reidy, E.B., Carr, D., Kessler, R., Nesse, R. and Wortman, C. 2004. The daily consequences of widowhood: The role of gender and intergenerational transfers of subsequent housework performance. Journal of Family Issues, 25, 5, 683-712.

Van IJzendoorn, M.H. and Bakermans-Kranenburg, M.J. 2010. Invariance of adult attachment across gender, age, culture , and socioeconomic status? Journal of Social and Personal Relationships, 27, 2, 200-8.

Van Tilburg, T. and De Leeuw, E. 1991. Stability of scale quality under various data collection procedures: A mode comparison on the De Jong Gierveld Loneliness Scale. International Journal of Public Opinion Research, 3, 1, 69-85.

Vogt Yuan, A.S. 2009. Sibling relationships and adolescents' mental health: The interrelationship of structure and quality. Journal of Family Issues, 30, 9, 1221-44.

Voorpostel, M. and Van der Lippe, T. 2007. Support between siblings and between friends: Two worlds apart? Journal of Marriage and Family, 69, 5, 1271-82. 
Voorpostel, M., Van der Lippe, T. and Flap, H. 2012. For better or worse. Negative life events and sibling relationships. International Sociology, 27, 3, 330-48.

Wenger, C.G., Davies, R., Shahtahmasebi, S. and Scott, A. 1996. Social isolation and loneliness in old age: Review and model refinement. Ageing \& Society, 16, 3, 333-58.

White, L. 2001. Sibling relationships over the life course: A panel analysis. Journal of Marriage and Family, 63, 2, 555-68.

Zeifman, D. and Hazan, C. 2008. Pair bonds as attachments. Reevaluating the evidence. In Cassidy, J. and Shaver, P.R. (eds.), Handbook of Attachment. Theory, Research, and Clinical Applications. Guilford, New York/London, 436-55.

Zunzunegui, M.V., Béland, F. and Otero, A. 2001. Support from children, living arrangements, self-rated health and depressive symptoms of older people in Spain. International Journal of Epidemiology, 30, 5, 1090-9. 
Table 1. Descriptive statistics of the study variables $(N=218)$

\begin{tabular}{|c|c|c|c|}
\hline Variables & $M$ & $S D$ & Range \\
\hline Gender ( $\%$ female $)$ & 77.52 & & $0-1$ \\
\hline Age (years) & 70.52 & 7.28 & $53-83$ \\
\hline Education & 4.93 & 2.73 & $1-11$ \\
\hline Partner status (\% repartnered) & 16.06 & & $0-1$ \\
\hline Health & 3.81 & 0.73 & $1-5$ \\
\hline Year widowhood & 1994 & 8.06 & $1961-2003$ \\
\hline Attachment to mother & 3.81 & 0.96 & $1-5$ \\
\hline Attachment to father & 3.56 & 0.95 & $1-5$ \\
\hline Number of children & 2.96 & 1.49 & $1-10$ \\
\hline Practical support from children & 1.47 & 0.48 & $1-3$ \\
\hline Emotional support from children & 2.41 & 0.53 & $1-3$ \\
\hline Number of siblings & 5.01 & 3.33 & $1-17$ \\
\hline Practical support from siblings & 1.08 & 0.24 & $1-3$ \\
\hline Emotional support from siblings & 1.79 & 0.57 & $1-3$ \\
\hline Evaluation of family ties & 4.13 & 0.59 & $1-5$ \\
\hline Loneliness & 3.65 & 2.98 & $1-11$ \\
\hline
\end{tabular}


Table 2. Correlations among demographic control variables, childhood memories, siblings support, family ties and loneliness $(N=218)$

\begin{tabular}{|c|c|c|c|c|c|c|c|c|c|c|c|c|c|c|c|}
\hline & 1 & 2 & 3 & 4 & 5 & 6 & 7 & 8 & 9 & 10 & 11 & 12 & 13 & 14 & 15 \\
\hline 1. Gender & - & & & & & & & & & & & & & & \\
\hline 2. Age (years) & .02 & - & & & & & & & & & & & & & \\
\hline 3. Education & $-.23 * *$ & -.07 & - & & & & & & & & & & & & \\
\hline 4. Partner status & - & $-.14 *$ & $.17 * *$ & - & & & & & & & & & & & \\
\hline 5. Health & $-.17 *$ & -.08 & $.19^{* *}$ & .11 & - & & & & & & & & & & \\
\hline 6. Year widowhood & $-.20 * *$ & -.11 & .12 & .02 & .02 & - & & & & & & & & & \\
\hline 7. Attachment to mother & -.10 & .06 & $-.23 * *$ & -.03 & .03 & -.01 & - & & & & & & & & \\
\hline 8. Attachment to father & -.04 & -.08 & $-.17 * *$ & -.04 & .03 & -.05 & $.21 * *$ & - & & & & & & & \\
\hline 9. Number of children & -.04 & $.30 * * *$ & -.09 & -.01 & -.01 & -.06 & .06 & .00 & - & & & & & & \\
\hline 10. Practical support from children & $.20^{* *}$ & -.03 & .08 & $-.17 *$ & -.11 & -.02 & -.04 & -.08 & -.12 & - & & & & & \\
\hline 11. Emotional support from children & $.22 * *$ & .04 & .08 & -.08 & -.07 & .10 & -.08 & -.01 & -.00 & $.33 * * *$ & - & & & & \\
\hline 12. Number of siblings & -.02 & .10 & $-.22 * *$ & -.07 & .09 & -.06 & .03 & -.08 & $.16^{*}$ & $.16^{*}$ & .07 & - & & & \\
\hline 13. Practical support from siblings & .06 & .00 & .01 & .04 & -.10 & .01 & .06 & -.08 & -.05 & $.23^{* *}$ & -.05 & -.00 & - & & \\
\hline 14. Emotional support from siblings & $.13^{*}$ & .09 & .03 & -.02 & -.07 & -.08 & .01 & -.05 & .06 & $.18^{* *}$ & $.34 * * *$ & -.11 & $.15^{*}$ & - & \\
\hline 15. Evaluation of family ties & $.14^{*}$ & .02 & -.07 & $-.15 *$ & .06 & .01 & $.27 * * *$ & $.24 * * *$ & -.06 & $.18^{* *}$ & $.23 * *$ & .01 & -.00 & $.16^{*}$ & - \\
\hline 16. Loneliness & -.12 & .01 & -.07 & -.07 & $-.27 * * *$ & .05 & -09 & $-.16^{*}$ & -.05 & -.12 & $-.23 * *$ & -.13 & -.01 & $-.15 *$ & $-.23 * *$ \\
\hline
\end{tabular}

Note. Gender and partner status are dummy coded, such that 1 is female and having a partner. ${ }^{\dagger} p<.10, * p<.05, * * p<.01, * * * p<.001$ 
Table 3. Family history predicting current family ties $(N=218)$

\begin{tabular}{|c|c|c|c|c|c|c|}
\hline \multirow[t]{2}{*}{ Predictors } & \multicolumn{3}{|c|}{ Step 1} & \multicolumn{3}{|c|}{ Step 2} \\
\hline & $B$ & $S E B$ & $\beta$ & $B$ & $S E B$ & $\beta$ \\
\hline \multicolumn{7}{|c|}{ Background characteristics } \\
\hline Gender & 0.22 & .10 & $0.15^{*}$ & 0.30 & .10 & $0.21 * *$ \\
\hline Age & 0.00 & .01 & 0.02 & 0.00 & .01 & 0.03 \\
\hline Education & -0.01 & .02 & -0.06 & 0.01 & .02 & 0.05 \\
\hline Health & 0.08 & .06 & 0.09 & 0.06 & .05 & 0.07 \\
\hline Year widowhood & 0.00 & .01 & 0.05 & 0.00 & .01 & 0.06 \\
\hline \multicolumn{7}{|c|}{ Family history characteristics } \\
\hline Attachment to mother & & & & 0.16 & .04 & $0.25 * * *$ \\
\hline Attachment to father & & & & 0.13 & .04 & $0.20 * *$ \\
\hline $\mathrm{R}^{2}$ & \multicolumn{3}{|c|}{.10} & \multicolumn{3}{|c|}{.22} \\
\hline $\mathrm{R}^{2}$ adj. & \multicolumn{3}{|c|}{.06} & \multicolumn{3}{|c|}{.17} \\
\hline Coll. & \multicolumn{3}{|c|}{$>.745$} & \multicolumn{3}{|c|}{$>.727$} \\
\hline
\end{tabular}

Note. Gender and partner status are dummy coded, such that 1 is female and having a partner. $* p<.05, * * p<.01, * * * p<.001$ 
Table 4. Family history, current family ties and the functioning of the family network predicting loneliness $(N=218)$

\begin{tabular}{|c|c|c|c|c|c|c|c|c|c|c|c|c|c|c|c|}
\hline \multirow[t]{2}{*}{ Predictors } & \multicolumn{3}{|c|}{ Model 1} & \multicolumn{3}{|c|}{ Model 2} & \multicolumn{3}{|c|}{ Model 3} & \multicolumn{3}{|c|}{ Model 4} & \multicolumn{3}{|c|}{ Model 5} \\
\hline & $B$ & $S E B$ & $\beta$ & $B$ & $S E B$ & $\beta$ & $B$ & $S E B$ & $\beta$ & $B$ & $S E B$ & $\beta$ & $B$ & $S E B$ & $\beta$ \\
\hline \multicolumn{16}{|l|}{ Background characteristics } \\
\hline Gender & -1.22 & .49 & $-0.17 *$ & -1.58 & .52 & $-0.22 * *$ & -0.89 & .50 & $-0.13 \dagger$ & -1.23 & .49 & $-0.17 *$ & -1.38 & .52 & $-0.19^{* * *}$ \\
\hline Age & -0.01 & .03 & -0.01 & -0.01 & .03 & -0.03 & 0.01 & .03 & 0.02 & 0.00 & .03 & 0.01 & 0.01 & .03 & 0.01 \\
\hline Education & -0.13 & .08 & $-0.12 \dagger$ & -0.12 & .08 & -0.11 & -0.10 & .08 & -0.09 & -0.81 & .08 & $-0.17 *$ & -0.14 & .08 & $-0.13 \dagger$ \\
\hline Health & -1.07 & .27 & $-0.26 * * *$ & -1.06 & .27 & $-0.26 * * *$ & -1.14 & .27 & $-0.28 * * *$ & -1.01 & .27 & $-0.25 * * *$ & -1.05 & .27 & $-0.26 * * *$ \\
\hline Year widowhood & 0.01 & .02 & 0.03 & 0.01 & .02 & 0.02 & 0.02 & .02 & 0.05 & 0.01 & .02 & 0.01 & 0.01 & .02 & 0.02 \\
\hline \multicolumn{16}{|l|}{ Family history } \\
\hline Attachment to mother & -0.19 & .22 & -0.06 & -0.18 & .21 & -0.06 & -0.24 & .21 & -0.08 & -0.21 & .21 & -0.07 & -0.23 & .21 & -0.07 \\
\hline Attachment to father & -0.41 & .21 & $-0.13 \dagger$ & -0.42 & .21 & $-0.14^{*}$ & -0.43 & .21 & $-0.14 *$ & -0.51 & .21 & $-0.17 *$ & -0.52 & .21 & $-0.17 *$ \\
\hline Current family ties & -0.78 & .35 & $-0.15^{*}$ & -0.85 & .34 & $-0.17 *$ & -0.51 & .35 & -0.10 & -0.62 & .34 & $-0.12 \dagger$ & -0.57 & .35 & -0.11 \\
\hline \multicolumn{16}{|l|}{ Current network } \\
\hline Partner status & & & & -0.72 & .32 & $-0.15^{*}$ & & & & & & & -0.78 & .32 & $-0.16^{*}$ \\
\hline Number of children & & & & & & & -0.15 & .13 & -0.08 & & & & -0.10 & .13 & -0.05 \\
\hline Practical support from children & & & & & & & -0.34 & .42 & -0.06 & & & & -0.18 & .44 & -0.03 \\
\hline Emotional support from children & & & & & & & -1.07 & .40 & $-0.19 * *$ & & & & -0.85 & .42 & $-0.15^{*}$ \\
\hline Number of siblings & & & & & & & & & & -0.15 & .06 & $-0.17 *$ & -0.13 & .06 & $-0.15^{*}$ \\
\hline Practical support from siblings & & & & & & & & & & -0.16 & .78 & -0.01 & -0.32 & .80 & -0.03 \\
\hline
\end{tabular}




\begin{tabular}{|c|c|c|c|c|c|}
\hline $\mathrm{R}^{2}$ & .16 & .18 & .20 & .20 & .25 \\
\hline $\mathrm{R}^{2}$ adj. & .13 & .15 & .16 & .16 & .19 \\
\hline Coll. & $>.836$ & $>.756$ & $>.789$ & $>.775$ & $>.697$ \\
\hline
\end{tabular}

Note. Gender and partner status are dummy coded, such that 1 is female and having a partner. $\dagger p<.10, * p<.05, * * p<.01, * * * p<.001$ 
Table 5. Comparing warm and weak sibling relationships; main themes $(N=18)$

\begin{tabular}{|c|c|}
\hline $\begin{array}{l}\text { The blessings of warm relationships with siblings } \\
\qquad(N=9)\end{array}$ & $\begin{array}{l}\text { The enduring discomfort of weak bonds with siblings } \\
\qquad(N=9)\end{array}$ \\
\hline $\begin{array}{l}\text { Positive quality of the bonds in the parental home } \\
\text { ( } 2 \text { interviewees) }\end{array}$ & $\begin{array}{l}\text { Negative quality of the bonds in the parental home } \\
\text { (2 interviewees) }\end{array}$ \\
\hline $\begin{array}{l}\text { High quality of the current sibling bonds } \\
\text { (4 interviewees) }\end{array}$ & Lack of support from siblings ( 2 interviewees) \\
\hline $\begin{array}{l}\text { Improvement in the quality of sibling bonds after widowhood } \\
\text { ( } 3 \text { interviewees) }\end{array}$ & $\begin{array}{l}\text { Events in later life were held responsible for weakening of the sibling } \\
\text { bond ( } 2 \text { interviewees) }\end{array}$ \\
\hline & Other themes ( 3 interviewees) \\
\hline
\end{tabular}

